\title{
A New Thermo-Regulator.
}

\section{BY}

M. J. GREENMAN.

The Wistar Institute of Anatomy and Biology.

Referring to Fig. 1, A is a steel tube 14" long and $3 / 4$ " internal diameter, closed at the lower end. This tube is filled with mercury and screwed tightly into the body of the regulator $B$. The gas passages through the regulator body consist of an inlet $\mathbf{C}$ and an outlet $\mathrm{D}$ both of which are fitted with $1 / 8$ " (inside diameter) iron pipe. Gas entering at $\mathrm{C}$ passes through to outlet $\mathrm{D}$ and is conveyed from this outlet through an $1 / 8$ " iron pipe to the Bunsen burner beneath the oven.

Extending vertically through the regulator body $B$ is a passage $3 / 8$ " in diameter from $\mathrm{E}$ to $\mathrm{F}$ and $1 / 4$ " in diameter from $\mathrm{F}$ to $\mathrm{G}$. Within this passage is a float $H$ which carries on a slender rod above a valve which fits a conical valve-seat at $G$. Extending from inlet $C$ around this valve to outlet $D$ is a by-pass I controlled by a screw valve $J$. When valve at $G$ is closed, gas may be allowed to pass from inlet $C$ to outlet $D$ by opening screw valve $J$. This is to supply gas for the pilot light.

The regulator is filled with mercury until the lower end of $\mathrm{H}$ is sufficiently submerged to float. The height of the mercury in the passage $\mathrm{E}-\mathrm{F}$ is regulated by the rod $\mathrm{K}$ extending down through the regulator body into the mercury tube $\mathrm{A}$. By forcing down this rod the mercury is displaced and rises in the passage E-F. Float $H$ fits loosely and touches the walls of the passage in which it is contained at four points at F. This float is grooved at its upper end as shown in enlarged section M. These grooves permit any mercury, which may by accident be forced above point $F$, to fall readily back into passage E-F. Likewise the opening $N$ will permit any mercury, forced by accident into tube $\mathrm{C}$, to fall back into its proper place in passage E-F. On account of the intense surface tension of mercury it is necessary for sensitive

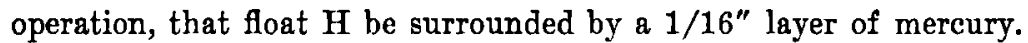

It will be seen now, that since $H$ floats in the mercury when about twothirds submerged, the slightest increase in the volume of the mercury contained in tube A, producing a considerable rise in the much smaller passage E-F, will carry float $H$ upward and close the valve at $G$. Since 
these changes in volume are produced by changes in temperature of the medium surrounding tube $A$ it will be seen that the gas valve at $G$ will open or close at the slightest change in temperature. Temperature is fixed by means of rod $\mathbf{K}$. Withdrawing the rod lowers the mercury in passage $\mathrm{E}-\mathrm{F}$, opens the gas valve at $\mathrm{G}$ and raises the temperature of bath or oven. Screw L by means of a stuffing box at the bottom, holds rod $K$ in place. The pin $O$ prevents the float $H$ from falling too far into the mercury tube.
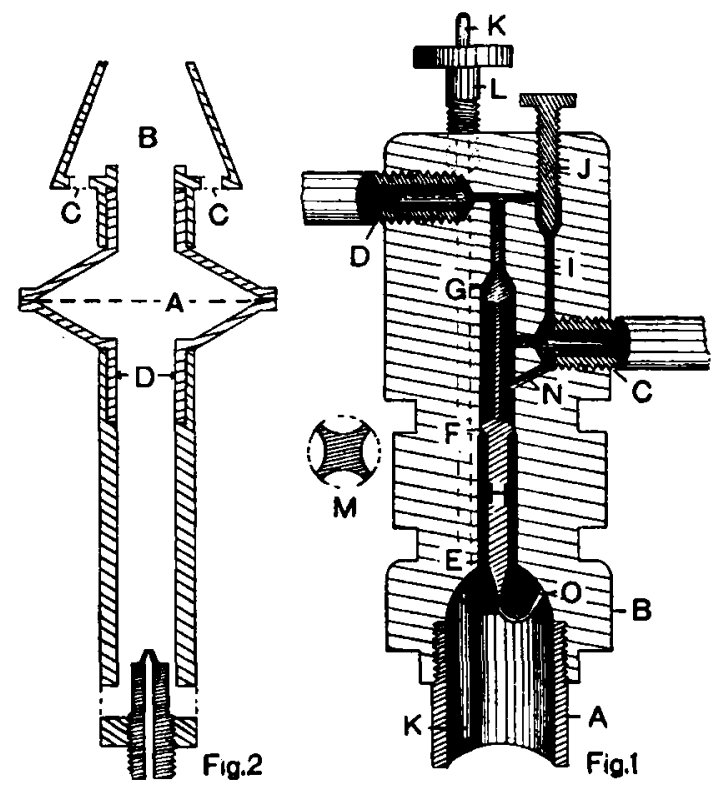

The Bunsen burner which operates best with this regulator is shown in Fig. 2. At $A$ is a copper gauze diaphragm $11 / 2^{\prime \prime}$ in diameter which, on account of size, does not retard the flow of gas, and does prevent the "snapping back," which so often occurs in other burners when the regulator reduces the gas flow to a very small amount.

The hood $B$ is to protect the pilot light which should burn just within this hood. When the gas flows freely, the extra air required is taken in through openings CC. A pilot light burning quite within this hood burns a blue flame, likewise when the burner operates at full capacity it burns a blue flame, thus preventing the troublesome sooting of the 
oven bottom. The height and bore of these burners must be determined by the maximum temperature required and the insulation of the oven. A burner having a $1 / 4$ " bore at $D$ suffices for an oven of 1 cubic foot internal capacity and operating at a temperature of $53^{\circ} \mathrm{C}$.

A similar oven operating at a temperature of $38^{\circ} \mathrm{C}$. would require a burner of $5 / 32^{\prime \prime}$ to $3 / 16^{\prime \prime}$ bore and somewhat shorter than the burner for higher temperatures. A burner of this type and of the proper capacity always burns a blue flame, and gives the greatest satisfaction.

The regulator here described is constructed entirely of steel and is designed for an oven of 1 cubic foot internal capacity. A larger oven requiring more gas would, of course, require a regulator having larger ports.

This regulator was designed to take the place of other thermo-regulators which have proven unsatisfactory and unsafe where gas is used for heating. It controls temperature within one-half of a degree regardless of gas pressure or room temperature.

Four of these regulators have been in successful operation in the laboratories of the Wistar Institute during the past season.

\author{
Embalming of Bodies for Teaching Purposes. \\ BX \\ EDMOND SOUCHON, M.D. \\ Professor Emeritus of Anatomy. Tulane University, New Orleans, La.
}

For some time past, I have been experimenting to improve the dissecting material at Tulane.

The first aim is, of course, thorough and complete preservation; second, the softness of the tissues, as they are found in the unembalmed subjects; third, the color of the muscles and organs, the scenring at lesst of a brown dark color for the muscles; fourth, the distention and the coloring of the arteries, without coloring the adjacent tissues.

After many experiments, the following formula have been reached by me and give almost perfect satisfaction, meeting the four requirements mentioned above.

Formula for Embatming Bodies for the Dissecting Room.

A.

Water ..................... one and a half gallons

Arsenious acid (saturated solution)........... one gallon

Formalln (formaldehyd $40 \%$ ) .............eight ounces 